\title{
Hydrogel of polysaccharide of sugarcane molasses as carrier of bone morphogenetic protein in the reconstruction of critical bone defects in rats ${ }^{1}$
}

\author{
Martinho Dinoá Medeiros JúniorI, Elaine Judite de Amorim Carvalho"I, Ivson Souza Catunda ${ }^{\mathrm{III}}$, Sidcley Bernardino-Araújo ${ }^{\mathrm{IV}}$, \\ José Lamartine de Andrade Aguiarv \\ IFellow PhD degree, Postgraduate Program in Surgery, UFPE, Recife-PE, Brazil. Main author. Conception, design, acquisition and interpretation of \\ data; manuscript writing. \\ IIAssociate Professor, Maxillofacial Surgery and Prothesis Department, UFPE, Recife-PE, Brazil. Analysis and interpretation of data, histopathogical \\ examinations. \\ IIIAssistant Professor, Maxillofacial Surgery Department, UFPE, Recife-PE, Brazil. Acquisition and interpretation of data.

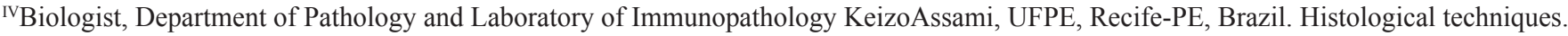 \\ ${ }^{v}$ Associate Professor, Department of Surgery, Postgraduate Program in Surgery, UFPE, Recife-PE, Brazil. Conception, design and supervised all \\ phases of the study, manuscript writing.
}

\section{ABSTRACT}

PURPOSE: To evaluate the benefit of using carriers such as the biopolymer gel (hidrogel of polysaccharide of sugarcane molasses) associated with the bone morphogenetic proteins (BMP's) in the repair of critical bone defects in calvaria of Wistar rats.

METHODS: Forty-two rats were submitted to a surgical calvaria bone defects. These animals were divided into two experimental groups, positive control group and negative control group. The Group I the calvaria defect was filled up with biopolymer gel, biological membrane, BMP and lyophilized graft. The Group II was treated with biopolymer gel, BMP and lyophilized graft. And the group III (positive control group) was treated with BMP, lyophilized graft and biological membrane. In the negative control group (Group IV) a defect was made in the rat calvaria and the animals were sacrificed immediately after the surgery. The animals of experimental groups and positive control group were slaughtered after subsequent periods of 90 and 180 days. In these periods, the histological analysis and image assessment by cone bean tomographic imaging were obtained.

RESULTS: There was highest bone tissue formation with statistically significant results in the groups that associated biopolymer gel and membrane (Group I), followed by the group III (BMP, lyophilized graft and biological membrane). The lower bone formation occurred in the group not using the sugarcane biopolymer gel (Group II). The radiolucent areas of the analyzes of 180 days among the groups studied were respectively, $14.98 \mathrm{~mm}^{2}, 26.65 \mathrm{~mm}^{2}$ and $35.81 \mathrm{~mm}^{2}$.

CONCLUSION: The biopolymer gel showed to be an excellent bone morphogenetic protein carrier, probably by facilitating the controlled release of these proteins in the process of bone repair.

Key words: Bone Regeneration. Bone Transplantation. Bone Morphogenetic Proteins. Rats. 


\section{Introduction}

The search for artificial substitutes or substances that promote bone tissue repair is a universal concern ${ }^{1}$. The first reports of substances inducing bone healing are attributed to Urist $\mathrm{t}^{1-4}$ that demonstrated, after isolation, the inducer activity of the bone morphogenetic protein (BMP) in the bone tissue regeneration, when studying the development of heterotopic bone after implantation of demineralized bone matrix in subcutaneous tissue and muscle of rats, designating the process of osteoinduction ${ }^{1,2,5,6}$. Then it was postulated that pluripotent mesenchymal stem cells are attracted by chemotaxis to the site of implantation, inducing formation of bone and cartilage. These factors were isolated and cloned, being then called bone morphogenetic proteins or BMP's.

Many carriers have been tested experimentally, using scaffolds composed of chitosan-gelatin blends ${ }^{7}$ or bioactive glass ${ }^{8}$ due to their bone regenerative properties, but the ideal material to carry the BMP's has not yet been defined, depending probably on the clinical indication for use of morphogenetic protein. The polysaccharide gel, associated with the substances tested, proved to be biocompatible with good properties to serve as a carrier.

A new material, with polymeric chemical structure, was obtained by synthesis from sugarcane molasses. The biopolymer is biocompatible, low toxicity, consisting only of sugar molecules and glucuronic acid and has physical and chemical characteristics suitable for use in grafting 9 . In different tissues, the application of biopolymer has shown adequate response by the organisms, showing biointegration and remodeling of tissues with features that allow for future applications ${ }^{10,11}$. This study assessed by CT imaging and histology, the ability to osteo-promotion of the association of biopolymer gel as carrier of bone morphogenetic protein and lyophilized bone grafts in the formation of a barrier compared to collagen membrane of bovine origin in the treatment of critical defects in rats calvarium in periods of 90 and 180 days after surgery.

\section{Methods}

The present study received approval from the Animals Research Ethics Committee of Pernambuco Federal University in the city of Recife, Brazil. Forty-two rats (Rattus norvegicus, Albinus, Wistar), male adults, 311 grams average weight from the vivarium of the Department of Antibiotics, UFPE were used in this study. Each group was composed of twelve animals, the animals were sacrificed after subsequent periods of 90 (six animal) and 180 days (six animal). Totaling four groups divided as follows:
Group I: Biopolymer gel + Biological Membrane of Bovine Origin (GenDerm ${ }^{\circledR}$ Baumer SA) + BMP (Genpro ${ }^{\circledR}$ Baumer SA) + lyophilized graft (Gen-ox inorg ${ }^{\circledR}$ Baumer SA);

Group II: Biopolymer gel + BMP (Genpro ${ }^{\circledR}$ Baumer SA) + lyophilized graft (Gen-ox inorg ${ }^{\circledR}$ Baumer SA);

Group III (positive control): Biological Membrane of Bovine origin $\left(\right.$ GenDerm ${ }^{\circledR}$ Baumer SA $)+$ BMP $\left(\right.$ Genpro ${ }^{\circledR}$ Baumer SA) + lyophilized graft (Gen-ox inorg ${ }^{\circledR}$ Baumer SA);

Group IV: Negative control group, composed of six animals, the animals were put down immediately.

Rats were anesthetized with $10 \%$ chloral hydrate intraperitoneal and the antisepsis was performed with iodine polyvinylpyrrolidone and tricomy of cranial region. The animals were placed in the prone position and covered with sterile surgical drapes. $1 \mathrm{ml}$ of $2 \%$ lidocaine chloridrate was infiltrate with 1:200.000 epinephrine into subcutaneous area operated. Elliptical incision performed on the anterior portions of the skull involving the skin, fascia and periosteum, dissection of the flap and osteotomy for creation of critical bone defect with $11 \mathrm{~mm}$ trephine under profuse irrigation with saline solution. The portion of the skull was removed with preservation of the sagittal sinus. The defects were filled with grafts, according to the composition of the groups studied. After periods of 90 and 180 days, the animals were sacrificed using an overdose of anesthetic.

The plans of interest were dissected with preservation of periosteum taken to obtain the images in a iCATVision tomography (3D cone-bean), Imaging Sciences International, which allowed the reconstruction of defects of images for measurement of bone formation within the radiolucent area found, observing whether there was significant difference between groups with regard to the measurement of radiolucency.

Histological analysis was performed after decalcification and staining of parts with hematoxylin-eosin and examined by light microscopy, seeking to evaluate the morphological aspects of cavity bone repair, as well as the closure evolution, trying to compare these data among the six groups studied.

To analyze the imaging data were obtained the statistical measures: mean, standard deviation, coefficient of variation, minimum and maximum value, descriptive statistics techniques, and used the tests Kruskal-Wallis with paired comparisons of Conover, 1980. It is noteworthy that the choice for nonparametric tests was due to the limited number of cases. The significance level used to define the statistical tests was $5.0 \%$. Data were entered in Excel spreadsheet and the software used to obtain statistical calculations was the SPSS (Statistical Package for Social Sciences) version 15 . 


\section{Results}

The results of the experimental groups with the biopolymer gel showed the highest bone formation in those whose membranes were used as barriers, thus demonstrating greater bone formation in the tomographic images obtained and in the histological qualitative analysis, with formation of this tissue farthest from the lesion edges, ie closest to the center and with bone tissue formation in various stages of calcification, without however, there being complete repair of the bone tissue in any group (Figures 1 and 2).

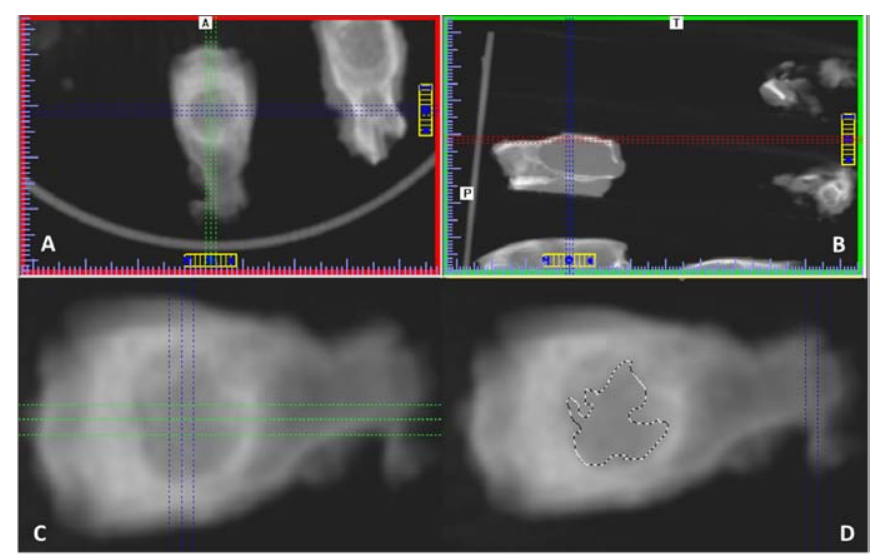

FIGURE 1 - (A/B). Selection of the samples with position adjustment for determination of radiolucent areas. (C/D). Delimitation of radiolucent area to be calculated.

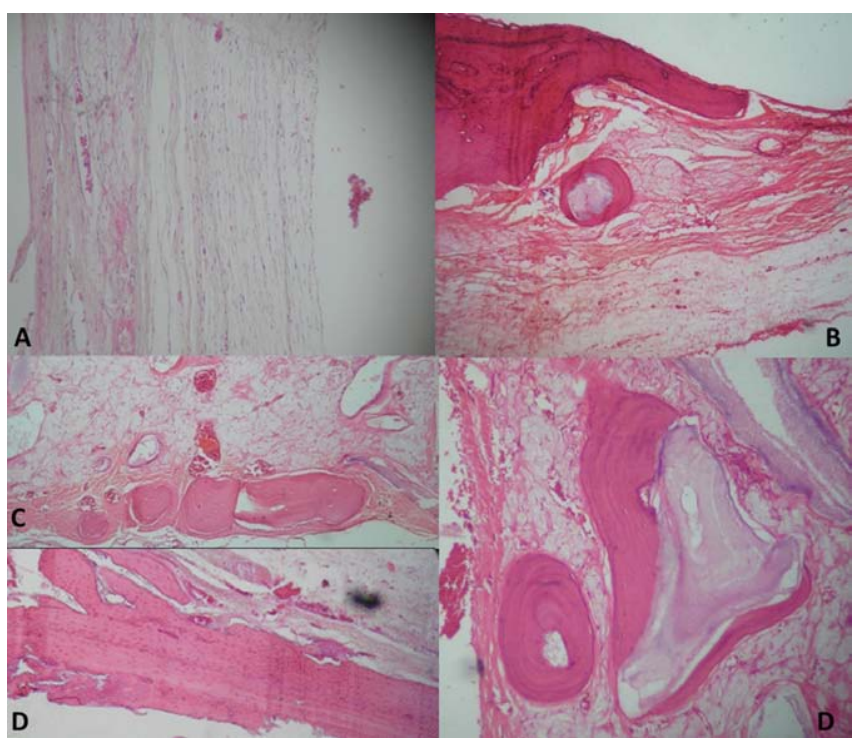

FIGURE 2 - A. (Group III - positive control) Membrane + BMP + Lyophilized graft 180 days - Organized fibrous connective tissue proliferative activity where there is congested vascular spaces (20x). B. (Group I) Gel + Membrane + BMP + Lyophilized graft 90 days - New bone formation at the edge of the defect, the Isle of bone formation with encapsulation of bone graft (20x). C. (Group I) Gel + Membrane + BMP + Lyophilized graft 180 days - Islands of new bone formation around the bone graft with bone formation (20x). D. (Group I) Gel + Membrane + BMP + Lyophilized graft 180 days - Significant bone formation in order to remedy the experimental defect (40x).
The imaging results showed that the presence of the membrane as a barrier, the BMP and the inorganic lyophilized bovine bone were carried quite effectively by the polysaccharide gel, since shown the groups of greater bone formation with decreased critical defects (Table 1, Figures 3 and 4).

TABLE 1 - Statistical analysis of the radiolucent area according to the time of evaluation and studied groups.

\begin{tabular}{|c|c|c|c|c|c|}
\hline $\begin{array}{c}\text { Evaluation } \\
\text { times }\end{array}$ & Group & Mean & SD & $\mathrm{CV}$ & Minimum Maximum \\
\hline
\end{tabular}

90 days $\quad \begin{gathered}\text { Gel+Membrane } \\ + \\ + \text { BMP+Lyophilized } \\ \text { graft(Group I) } \\ \text { Gel + BMP + }\end{gathered}$

\begin{tabular}{|c|c|c|c|c|c|c|}
\hline Valor de p & & \multicolumn{5}{|c|}{$\mathrm{p}^{(1)}<0.009^{*}$} \\
\hline \multirow[t]{4}{*}{180 days } & $\begin{array}{c}\text { Gel+Membrane } \\
+ \text { BMP+Lyophilized } \\
\text { Graft (Group I) }\end{array}$ & $14.98^{(\mathrm{B})}$ & 3.65 & 24.37 & 8.55 & 18.82 \\
\hline & $\begin{array}{c}\text { Gel + BMP + } \\
\text { Lyophilized } \\
\text { graft (Group II) }\end{array}$ & $26.65^{(\mathrm{B})}$ & 2.92 & 10.96 & 22.36 & 29.73 \\
\hline & $\begin{array}{c}\text { Membrane+BMP } \\
\text { +Lyophilized } \\
\text { graft(Group III) }\end{array}$ & $35.81^{\text {(A) }}$ & 19.74 & 55.12 & 13.49 & 64.46 \\
\hline & Negative Control & $92.96^{\text {(D) }}$ & 1.35 & 1.45 & 92.04 & 93.94 \\
\hline Valor de p & & $\mathrm{p}^{(\mathbf{1})}<0.001$ & & & & \\
\hline
\end{tabular}

1) Through the Kruskal-Wallis test with pair wise comparisons according to the methodology presented in Conover.

Note: If the letters in parentheses are distinct, the significant difference among the corresponding groups is proved. 


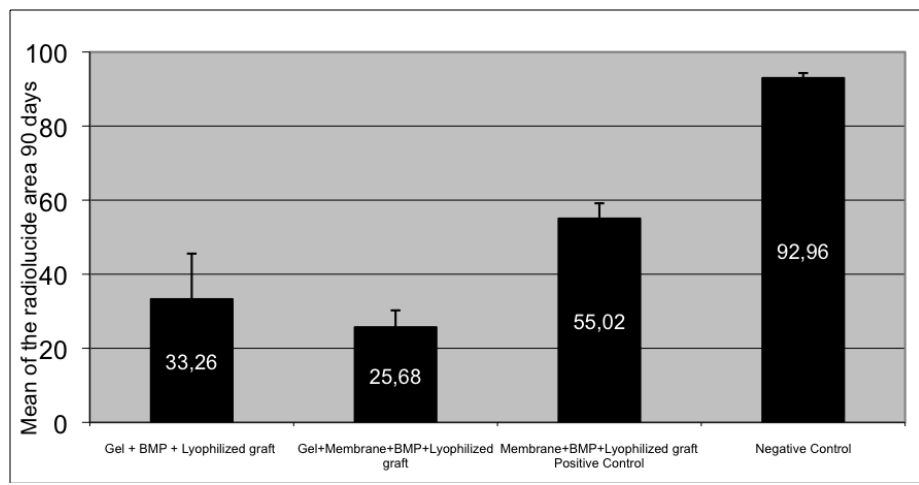

FIGURE 3 - Mean and standard deviation of the radiolucent area according to the group with 90 days evaluation.

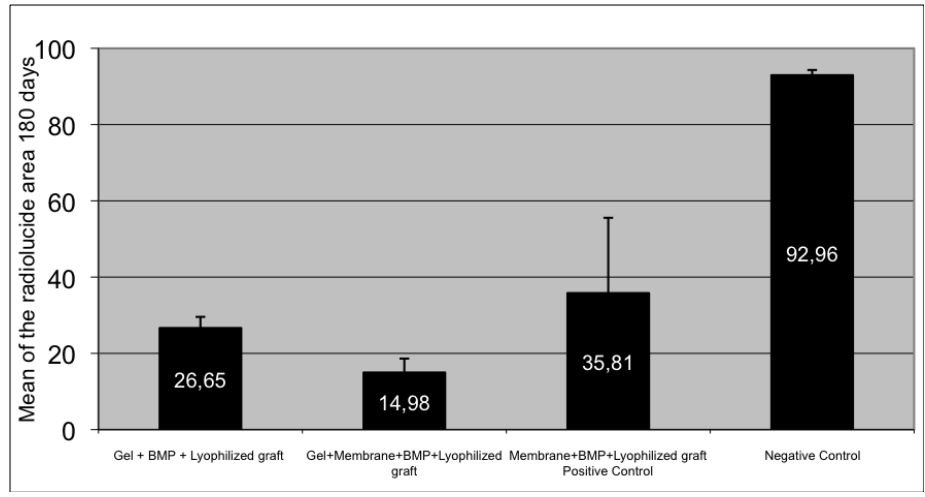

FIGURE 4 - Mean and standard deviation of the radiolucent area according to the group with 180 days evaluation.

\section{Discussion}

This study assessed by histology and imaging, the ability to osteopromotion of the association of polysaccharide gel as carrier, the bone morphogenetic protein, lyophilized bone grafts and collagen membrane for the treatment of critical defects in rat calvarium in periods from 90 and 180 days after surgery.

The repair of defects is a good model for studying the regeneration of bone and has a great resemblance to the primary repair or direct of fractures.

Whereas the defects are less subject to mechanical factors and obstruction of blood supply, this model of bone repair is used in classical experiments ${ }^{12,13}$ that analyzed the influence of surgical and pharmacological measures to improve bone regeneration.

The critical defects were used in this study by being experimental bone defects with great dimensions for not occurring spontaneous repair, once only in this situation, the osteogenic potential of the graft may be considered real.

Thus, it can be considered without error the osteogenic potential of the test material.

We used the principle Guided Bone Regeneration $(\mathrm{ROG})^{14,15}$, with the use of collagen membrane. This technique consists in using biological membrane to form a physical barrier, creating an appropriate environment, protected against competing cell invasion, less differentiated and highly proliferative of surrounding tissues, especially fibroblasts and epithelial cells and promoting cell proliferation characteristic of the region for regeneration of the natural tissues in the area.

The membranes used had the format equal to the defect, circular, no angles at the edges. The edges of membranes were at a distance of 2 or $3 \mathrm{~mm}$ beyond the defect edge. The right angles can cause disruption in retail and in the periosteum, exposing the surgical site, the graft material or even the membrane to the environment, favoring the formation of bacterial colonies and starting the infection process with subsequent inflammation in the region, jeopardizing the regenerative process requested.

This research used what is called in literature "pool" of BMP's; this BMP's composition comprises a mixture of this factor without separation of the subfamilies. The BMP's were used at a dilution of one part of the Gen-Pro ${ }^{\circledR}$ (BMP) to ten parts of inorganic lyophilized bovine bone (Gen-inorg $\left.{ }^{\circledR}\right)$. The dilution was made based on the manufacturer's recommendation.

BMP is a diffusible protein, and to start the process osseoindutive in vivo it is necessary its gradual release, which can be obtained with the use of carriers. The association with organic and inorganic lyophilized bone substances is needed, and this study aimed at adding the polysaccharide gel to stabilize this association of grafts. It took into account that the kinetics of a carrier has a profound effect on the speed and efficacy of bone induction. The primary function is to increase the BMP's efficiency and preventing the rapid diffusion of the inductive agent away from the implant site and by the existence of a sustained protein release.

It is worth noting that the investigations grow in order to determine the best type of carrier material in the release of BMP's in clinical indications. For treatment of fracture repair, the release must be combined with a material that meets the new bone formation rate, so that transport the material and does not compromise the healing.

In this sense, materials that can improve the BMP stability in the medium of which will grafted, will serve of increment in the qualitative properties of bone formation. The polysaccharide gel was associated with grafts used in order to observe their behavior in this type of tissue, as well as its function controlled release of BMP's. It is a recent material, not yet used as a carrier in the repair of bone defects and has demonstrated biocompatibility and low cytotoxicity in studies[9-11] that preceded this research.

In all segments of studies on the biopolymer, the response of animals is significantly biocompatible. Those with remained with 
the polymer for over a year, there was a biointegration expressed by pronounced vascular neoformation within the polymer, defining a polymer incorporation to the recipient organism. In rats that remained with the biopolymer in the presentation of gel, screens and suture wires, no side effects were detected. Comparative observational studies in animals, between the polymer and other materials, commonly used in humans, although even without data for completion of statistical studies, showed the biopolymer superiority $^{16-21}$.

In this study of bone repair was observed that during surgical procedures, when the gel was incorporated into the grafts substances in the form of carrier, the transurgical bleeding was evidently controlled. Therefore, there is another property to be searched with the use of gel.

This research was used to capture images of postsurgical bone defects using cone beam CT. Proved to be feasible in implementation, as overlapping the base of the skull in radiographs left obscure the results obtained. This imaging tool has allowed turning the skull in the desired direction and standardizing the method of data collection, since turning the skull in the anteriorposterior and laterolateral directions was extremely important to get the desired cuts.

Regarding the histological study, the model used in this study was to evaluate the ability of combining substances, classically inducer of osteogenesis carried by biopolymer gel. This combination of substances comprised inorganic bovine bone matrix in orthotopic site, ie, bone site where the micro environmental conditions are more favorable to the occurrence of induced osteogenesis. Since all bone defects have remained open, the results were highly significant, once bone repair that occurred in the treated bone defects can only be attributed to association of substances containing the gel of polysaccharides, as a carrier for BMP's with inorganic xenogenic bone matrix, used to fill in the lesions.

Resorption of cortical bovine bone membrane was observed in all groups, since it is a biological resorbable membrane. At 90 days, the membranes would have gone through this process. The formation of bone tissue and integrator tissue were analyzed in combination, as in all groups there was the formation of a fibrous tissue by connecting the edges of the remaining bone defect. There were varying degrees of bone formation in all groups, forming islands of hard tissue and evident bone formation from the edges, quantified in the study of imaging, although it has not been complete closure of the defect, characterizing it as critical defect, promoting safety at work regarding the results.

Many carriers have been tested experimentally, but the ideal material to carry the BMP's has not yet been defined, depending, probably on the clinical indication for use of morphogenetic protein. The polysaccharide gel, associated with the substances tested, proved to be biocompatible with good properties to serve as a carrier.

\section{Conclusions}

The polysaccharide gel has proven to be biocompatible and may be used in bone tissue research.

The results suggest that the gel of polysaccharides associated with lyophilized bone, can be used as an effective carrier for the BMP's in the stimulation of bone repair as well as provide suitable consistency for filling osseous defects and properties that facilitate a controlled protein release.

\section{References}

1. Urist MR. Bone formation by autoinduction. Science. 1965;150(3698):893-9.

2. Urist MR, Strates BS. Bone morphogenetic protein. J Dent Res. 1971;50(6):1392-406.

3. LiRH, Wozney JM. Delivering on the promise of bone morphogenetic proteins. Trends Biotechnol. 2001;19(7):255-65.

4. Wozney JM, Rosen V, Celeste AJ, Mitsock LM, Whitters MJ, Kriz RW, Hewick RM, Wang EA. Novel regulators of bone-formation molecular clones and activities. Science. 1988;242(4885):1528-34.

5. Urist MR, Strates BS. The classic: bone morphogenetic protein. Clin Orthop Relat Res. 2009;467(12):3051-62.

6. Urist MR. Bone: formation by autoinduction. Clin Orthop Relat Res. 2002(395):5-10.

7. Miranda SC, Silva GA, Mendes RM, Abreu FA, Caliari MV, Alves JB, Goes AM. Mesenchymal stem cells associated with porous chitosan-gelatin scaffold: A potential strategy for alveolar bone regeneration. J Mater Biomed Res A. 2012;100(10):2775-86.

8. Bi L, Jung S, Day D, Neidig K, Dusevich V, Eick D, Bonewald L. Evaluation of bone regeneration, angiogenesis, and hydroxyapatite conversion in critical-sized rat calvarial defects implanted with bioactive glass scaffolds. J Mater Biomed Res A. 2012;100(12):326775.

9. Paterson-Beedle M, Kennedy JF, Melo FAD, Lloyd LL, Medeiros V. A cellulosic exopolysaccharide produced from sugarcane molasses by a Zoogloea sp. Carbohyd Polym. 2000;42(4):375-83.

10. Falcao SC, Evencio Neto J, Coelho AR. Incorporation by host tissue of two biomaterials used as repair of defects produced in abdominal wall of rats. Acta Cir Bras. 2008;23(1):78-83.

11. Aguiar JL, Lins EM, Marques SR, Coelho AR, Rossiter Rde O, Melo RJ. Sugarcane biopolymer patch in femoral artery angioplasty on dogs. Acta Cir Bras. 2007;22 Suppl 1:77-81.

12. Gosain AK, Song L, Yu P, Mehrara BJ, Maeda CY, Gold LI, Longaker MT. Osteogenesis in cranial defects: reassessment of the concept of critical size and the expression of TGF-beta isoforms. Plast Reconstr Surg. 2000;106(2):360-71.

13. Gosain AK, Song L, Yu P, Mehrara BJ, Maeda CY, Gold LI, Longaker MT. Quantitative assessment of cranial defect healing and correlation with the expression of TGF-beta. J Craniofac Surg. 
2001;12(4):401-4

14. Dahlin C, Linde A, Gottlow J, Nyman S. Healing of bone defects by guided tissue regeneration. Plast Reconstr Surg. 1988;81(5):672-6.

15. Dahlin C, Alberius P, Linde A. Osteopromotion for cranioplasty. An experimental study in rats using a membrane technique. J Neurosurg. 1991;74(3):487-91.

16. Lima FR, Lima JRA, Hirakawa P, Medeiros Júnior MD, Lima FMT, Aguiar JLA. Resposta inflamatória a membranas de biopolímero de cana-de-açúcar e telas de polipropileno ${ }^{\circledR}$ implantadas no peritôneo parietal de ratos. An Fac Med Univ Fed Pernamb. 2005;50(1):37-40

17. Marques SRB, Lins EM, Aguiar JLA, Albuquerque MCS, Rossiter RO, Montenegro LT, Vieira RJ. A new vascular substitute: femoral artery angioplasty in dogs using sugarcane biopolymer membrane patch - hemodynamic and histopathologic evaluation. J Vasc Bras. 2007;6(4):309-15.

18. Mayer DLB, Araújo JG, Leal MC, Caldas Neto SS, Ataíde RF, Mello RJV. Membrana do biopolímero da cana-de-açúcar: avaliação experimental na orelha média. Braz J Otorhinolaryngol. 2011;77(1):44-50

19. Albuquerque PCVC, Aguiar JLA, Santos SM, Pontes Filho N, Mello RJV, Costa MLCR, Albuquerque CMC, Almeida TMS, Santos AHS, Silva JC. Comparative study of the areas of osteochondral defects produced in the femoral condyles of rabbits treated with gel of sugarcane biopolymer. Acta Cir Bras. 2011;26(5):383-6.

20. de Barros-Marques SR, Marques-Lins E, de Albuquerque MC, de Andrade-Aguiar JL. Sugarcane biopolymer patch in femoral vein angioplasty on dogs. J Vasc Surg. 2012;55(2):517-21.

21. Cordeiro-Barbosa F de A, Aguiar JL, Lira MM, de Pontes Filho NT, Bernardino-Araújo S. Use of a gel biopolymer for the treatment of eviscerated eyes: experimental model in rabbits. Arq Bras Oftalmol. 2012;75(4):267-72.

\section{Acknowledgments}

To Dr. Marcos Frazão for his advice and encouragement and help in developing instrumentation in the early phases of this study.

\section{Correspondence:}

Martinho Dinoá Medeiros Júnior

Universidade Federal de Pernambuco

Departamento de Cirurgia-Coordenação de Pós-graduação

Avenida Professor Moraes Rego, 1235

50670-901 Recife - PE Brasil

Tel.: (55 81)2126-3518

drmdinoa@yahoo.com.br

Received: December 12, 2012

Review: February 14, 2013

Accepted: March 12, 2013

Conflict of interest: none

Financial source: National Council of Technological and Scientific Development (CNPq)

${ }^{1}$ Research performed at Experimental Surgery Center, Department of Surgery, Pernambuco Federal University (UFPE), Recife-PE, Brazil. Part of $\mathrm{PhD}$ degree thesis, Postgraduate Program in Surgery. Tutor: Prof. José Lamartine de Andrade Aguiar. 